\title{
Multidrug Resistance of Neisseria gonorrhoeae: Antibiotic Stewardship and Prospective Treatment Alternatives
}

\author{
Marvellous Oluebube Asika ${ }^{1}$, Emmanuel Ebuka Elebesunu (iD ${ }^{1,{ }^{*}}$ and Joel Kosisochukwu Edeh ${ }^{1}$ \\ ${ }^{1}$ Department of Medical Laboratory Sciences, University of Nigeria, Enugu Campus, Enugu, Nigeria \\ "Corresponding author: Department of Medical Laboratory Sciences, University of Nigeria, Enugu Campus, Enugu, Nigeria. Email: elebesunumichael@gmail.com \\ Received 2020 December 06; Revised 2021 November 09; Accepted 2021 December 21.
}

Keywords: Antibiotic Resistance, Antimicrobials, Drugs, Neisseria gonorrhoeae, Treatment

\section{Dear editor,}

The growing rates of Neisseria gonorrhoeae resistance to antibiotics is a major threat to public health worldwide, as recent cases of gonorrhea are becoming increasingly difficult to treat. Gonorrhea is a highly prevalent sexually transmitted disease caused by a strict human pathogen known for its ability to adapt to and evade the defensive responses of the host immune system, which is the primary reason for the capability of causing repeated infections in humans (1). The bacteria primarily infect the urogenital tract but might also infect the anal and oral cavity. If left untreated, it might cause complications, such as pelvic inflammatory disease, epididymitis, and infertility (2).

Numerous antibiotics have been produced since the 1930s to combat gonococcal infections; however, alarmingly, the bacterial strains have progressively developed resistance to almost all of them. Penicillin was an effective first-line drug for gonorrhea treatment in the early 1940s; nevertheless, within 10 - 15 years, the susceptibility of the bacteria to this drug dropped quickly due to chromosomal mutations and the acquisition of penicillinresistant genes (1). By the 1970s, high-level resistance to penicillin was reported in Africa and Asia. Furthermore, by the 1980 s, there was a spike in treatment failures worldwide (1). Between the 1940s and 1960s, other antibiotics, such as macrolides, aminoglycosides, and tetracycline, were produced and used (1). During this period, fluoroquinolones were very effective in gonorrhea treatment; however, gonococcal strains resistant to these drugs also quickly emerged, and by 2007 such strains had spread to various countries worldwide, automatically limiting the use of fluoroquinolones for gonorrhea treatment (3).

The third-generation cephalosporins, cefixime, and ceftriaxone became the next first-line drugs for gonorrhea treatment due to their high efficacy (1). However, cefiximeresistant strains have been recently reported in Japan and Europe and will most likely spread globally (4). This alarming multidrug resistance (MDR) exhibited by $N$. gonorrhoeae has led to the bacteria being termed "superbugs" by the Centers for Disease Control and Prevention (CDC) (1). Currently, the recommended treatment for gonococcal infections by the CDC is a combination therapy involving a single dose of $250 \mathrm{mg}$ ceftriaxone administered intramuscularly and a single dose of $1 \mathrm{~g}$ azithromycin given orally (5). This has proven to be highly effective in gonorrhea treatment, as the combined action of both antibiotics is enough to clear out the infection, even for strains resistant to either of the drugs.

Unfortunately, some gonococcal strains have been identified with an increased minimum inhibitory concentration (MIC) for both azithromycin and ceftriaxone. In 2016, eight isolates of $N$. gonorrhoeae extracted from seven patients in Hawaii, USA, had extremely high MICs of $>256$ $\mu \mathrm{g} / \mathrm{mL}$ for azithromycin and $0.125-0.25 \mu \mathrm{g} / \mathrm{mL}$ for ceftriaxone (6), indicating that these isolates developed resistance to the combination therapy. Genetic analysis showed that these isolates were closely related and might have come from a single strain circulating locally (6). Additionally, an isolate resistant to both azithromycin and ceftriaxone was discovered in a patient with gonococcal pharyngitis in the United Kingdom after treatment failure using a combination therapy of $1 \mathrm{~g}$ azithromycin and $500 \mathrm{mg}$ ceftriaxone (6). This is problematic as the azithromycin-ceftriaxone dual therapy is the last resort for gonorrhea treatment and indicates the possibility of gonorrhea becoming untreatable in the nearest future. A recent update from the CDC advises against the continuous use of azithromycinceftriaxone dual therapy due to concerns about the possible adverse effects it could cause to commensal organ-

Copyright ( ) 2021, International Journal of Infection. This is an open-access article distributed under the terms of the Creative Commons Attribution-NonCommercial 4.0 International License (http://creativecommons.org/licenses/by-nc/4.0/) which permits copy and redistribute the material just in noncommercial usages, provided the original work is properly cited. 
isms and other bacterial pathogens usually resident in humans as microflora (7). Observing the low incidence of drug resistance to ceftriaxone, the CDC currently recommends only ceftriaxone (500 $\mathrm{mg}$ intramuscular dose) as the treatment for gonorrhea infections (7).

In light of the above-mentioned findings, it is necessary to seek alternatives to antibiotics for gonorrhea treatment, as the constant use of antibiotics finally yields antibiotic resistance. Some promising alternatives include the use of bacteriophages, phage lytic enzymes, predatory bacteria, and antimicrobial peptides. Studies on bacteriophages have shown their effectiveness in decreasing bacterial load in infections (8); therefore, they could be suitable for gonorrhea treatment. Phage lytic enzymes extracted from bacteriophages have been used in studies to treat Escherichia coli infections in mice and can be experimented with for N. gonorrhoeae infections (8). Certain antimicrobial peptides called Bacteriocins have been extracted from probiotic bacteria, with the similar ability of antibiotics to target and destroy certain parts of a pathogenic bacteria cell, utilizing different mechanisms (9).

Further research can be carried out on their suitability for gonococcal infections. Studies using predatory bacteria, such as Micavibrio spp. and Bdellovibrio spp., have shown that they possess the ability to prey on gramnegative multidrug-resistant bacteria without causing any harm to the host (10); therefore, their predatory action could be used against $N$. gonorrhoeae, which is also a gramnegative MDR organism. Moreover, great attention has been channeled toward the use of herbs for gonorrhea treatment. Various studies have proven that herbal remedies, such as garlic, apple cider vinegar, goldenseal, Aloe vera, and numerous others, are effective in resolving gonococcal infections (11). Such herbal products can be further investigated, processed, and purified pharmaceutically to develop new drugs with potent action against multidrugresistant gonorrhea.

A common advantage of these alternatives is their specificity for particular disease-causing bacteria without harming other host commensal microbes. On the flip side, the disadvantage is that none of them is as potent as traditional antibiotics; consequently, they might need to be administered as adjuncts to antibiotics. Furthermore, these alternatives are still under research and development; therefore, the potential of utilizing them for the treatment of MDR diseases is still far-off, despite significant progress. The development of a gonorrhea vaccine has also been tried; to date, four gonorrhea vaccine candidates have been developed in human clinical trials; however, none of them has shown substantial protective results (12). Interestingly, the serogroup B vaccine MeNZB used against Neisseria meningitidis showed a $31 \%$ effective- ness against gonorrhea infection in vaccinated subjects. This is because $N$. meningitidis and $N$. gonorrhoeae are genetically similar organisms, despite causing different diseases (12). Although MeNZB is not currently available, a similar vaccine called Bexsero was produced, which also showed the same cross-protection against gonorrhea (12). Such vaccines give hope that the production of an effective gonorrhea vaccine could be possible but requires further research and development efforts to make it a reality.

In summary, the MDR of N. gonorrhoeae is a global medical challenge that should be tackled urgently, or we could face the possibility of gonorrhea becoming untreatable. A possible solution could be using antibiotic alternatives for treatment, as this would help reduce the rate of antibiotic use and subsequently decrease gonococcal resistance. Several budding alternatives are being looked into, each with its own advantages and disadvantages. No single alternative might completely replace antibiotics; nevertheless, they have shown promising results. There is a need to strengthen efforts in the research and development of suitable alternatives for gonorrhea treatment.

\section{Footnotes}

Authors' Contribution: The concept and draft of this manuscript were developed by Marvellous Oluebube Asika, Emmanuel Ebuka Elebesunu, and Joel Kosisochukwu Edeh. Marvellous Oluebube Asika and Emmanuel Ebuka Elebesunu assisted with language edits. Joel Kosisochukwu Edeh assisted with data collection. All the authors have read and approved the final manuscript.

Conflict of Interests: The authors declare no conflict of interest.

Funding/Support: The authors did not receive any funding for the research and preparation of this manuscript.

\section{References}

1. Unemo M, Shafer WM. Antibiotic resistance in Neisseria gonorrhoeae: origin, evolution, and lessons learned for the future. Ann NY Acad Sci. 2011;1230:19-28. doi: 10.1111/j.1749-6632.2011.06215.x. [PubMed: 22239555]. [PubMed Central: PMC4510988].

2. Dela H, Attram N, Behene E, Kumordjie S, Addo KK, Nyarko EO, et al. Risk factors associated with gonorrhea and chlamydia transmission in selected health facilities in Ghana. BMC Infect Dis. 2019;19(1):425-33. doi: 10.1186/s12879-019-4035-y. [PubMed: 31096920]. [PubMed Central: PMC6524331].

3. CDC. Update to CDC's sexually transmitted diseases treatment guidelines: fluoroquinolones no longer recommended for treatment of gonococcal infections. Centers for Disease Control and Prevention (CDC); 2006, [cited 16 October 2020]. Available from: https://www.cdc.gov/mmwr/ preview/mmwrhtml/mm5614a3.htm. 
4. Tapsall JW, Ndowa F, Lewis DA, Unemo M. Meeting the public health challenge of multidrug- and extensively drug-resistant Neisseria gonorrhoeae. Expert Rev Anti Infect Ther. 2009;7(7):821-34. doi: 10.1586/eri.09.63. [PubMed:19735224].

5. Workowski KA, Bachmann LH, Chan PA, Johnston CM, Muzny CA, Park I, et al. Sexually Transmitted Infections Treatment Guidelines, 2021. Morb Mortal Recomm Rep. 2021;70(4):1-187. doi: 10.15585/mmwr.rr7004a1. [PubMed: 34292926]. [PubMed Central: PMC8344968].

6. Papp JR, Abrams AJ, Nash E, Katz AR, Kirkcaldy RD, O'Connor NP, et al. Azithromycin Resistance and Decreased Ceftriaxone Susceptibility in Neisseria gonorrhoeae, Hawaii, USA. Emerg Infect Dis. 2017;23(5):8302. doi: 10.3201/eid2305.170088. [PubMed: 28418303]. [PubMed Central: PMC5403062].

7. St Cyr S, Barbee L, Workowski KA, Bachmann LH, Pham C, Schlanger $\mathrm{K}$, et al. Update to CDC's Treatment Guidelines for Gonococcal Infection, 2020. Morb Mortal Wkly Rep. 2020;69(50):1911-6. doi: 10.15585/mmwr.mm6950a6. [PubMed: 33332296]. [PubMed Central:
PMC7745960].

8. Sillankorva S, Pereira MO, Henriques M. Editorial: Antibiotic Alternatives and Combinational Therapies for Bacterial Infections. Front Microbiol. 2018;9:3359. doi: 10.3389/fmicb.2018.03359. [PubMed: 30713532]. [PubMed Central: PMC6346700].

9. Cotter PD, Ross RP, Hill C. Bacteriocins: A viable alternative to antibiotics? Nat Rev Microbiol. 2013;11(2):95-105. doi: 10.1038/nrmicro2937. [PubMed: 23268227].

10. Kadouri DE, To K, Shanks RM, Doi Y. Predatory bacteria: a potential ally against multidrug-resistant Gram-negative pathogens. PLoS One. 2013;8(5). e63397. doi: 10.1371/journal.pone.0063397. [PubMed: 23650563]. [PubMed Central: PMC3641118].

11. Nazer M, Abbaszadeh S, Darvishi M, Kheirollahi A, Shahsavari S, Moghadasi M. The Most Important Herbs Used in the Treatment of Sexually Transmitted Infections in Traditional Medicine. Sud JMed Sci. 2019;14(2):41-64. doi: 10.18502/sjms.v14i2.4691.

12. Seib KL. Gonorrhoea vaccines: a step in the right direction. Lancet. 2017;390(10102):1567-9. doi: 10.1016/s0140-6736(17)31605-7. 